\title{
ESTROM, Environmental Science and Technology in Romania-programme overview
}

\author{
Walter Giger • Nicolae Panin
}

Received: 26 May 2009 / Accepted: 28 May 2009 / Published online: 17 June 2009

(C) Springer-Verlag 2009

Keywords Environmental Science - Romania ESTROM · Water pollutants $\cdot$ Wastewater $\cdot$ Rivers $\cdot$ Lakes $\cdot$ Sediments . Drinking water

The Swiss National Science Foundation (SNSF) and the Swiss Agency for Development and Cooperation (SDC) have been supporting research collaboration between Switzerland and Eastern European countries in the socalled Swiss Co-operation between Eastern Europe and Switzerland (SCOPES) programmes since 1990. A bottomup approach enabled researchers from Eastern Europe and Switzerland to collaborate in partnership projects (joint research projects and institutional partnerships). In 2003, the SNSF and SDC decided to launch a directed research programme meaning that proposals would be invited based on a published implementation plan. The successful National Research Programmes of SNSF served as models

Responsible editor: Walter Giger

ESPR Special Issue-ESTROM

W. Giger $(\bowtie)$

GRC, Giger Research Consulting,

8049 Zurich, Switzerland

e-mail: giger@giger-research.ch

W. Giger

Eawag, Swiss Federal Institute of Aquatic Science and Technology,

8600 Dübendorf, Switzerland

N. Panin

GeoEcoMar, National Institute for Marine Geology

and Geoecology,

024053 Bucharest, Romania for the new practice-oriented research initiative. Romania was selected as the partner country, and environmental research was chosen as a theme out of several Romanian proposals. Subsequently, an international Steering Committee decided to focus the programme on applied research in the area of water pollution and to name it ESTROM meaning Environmental Science and Technology in Romania. ESTROM has, from the start, been implementation-oriented in order to provide models for action at the political and policy level in line with the overall transition process as well as the compliance to EU legislation and international standards.

Members of the ESTROM Steering Committee were:

- Walter Giger (President), Swiss Federal Institute of Aquatic Science and Technology (Eawag), Dübendorf, Switzerland;

- Ulrich Ochsenbein (Vice-President), Office for Water Protection and Waste Management, Berne, Switzerland;

- Ioan Bocsan, Iuliu Hatieganu University, Cluj-Napoca, Romania;

- Nicolae Panin, Institute GeoEcoMar, Bucharest, Romania;

- Antonius Kettrup, Technical University Munich, Germany.

While developing the ESTROM implementation plan, a graphic synopsis on the issues of "Water pollutants in the aquatic environment" was used to illustrate the complexity of this topic (Fig. 1). The major thrust of ESTROM was to include projects in various environmental compartments and scientific topics from inputs of water pollutants via exposure analyses and risk assessments to mitigation measures.

Specific goals of the ESTROM programme were:

- to improve the knowledge on environmental occurrence and effects of water pollution due to chronic or acute anthropogenic impacts; 
Fig. 1 Water pollutants: from input sources via environmental fate and effects to risk assessment and risk reduction. Thorough analyses of exposures to chemical pollutants in wastewaters and assessments of associated risks to ecosystems and humans are aimed at leading to risk reduction and mitigation measures with a strong emphasis on reducing the inputs at the sources. The complexity of technical and natural aquatic systems with the many different compartments as well as characteristic system properties and dynamics must be considered. It is evident that problems of water pollutants must be tackled by an interdisciplinary approach

\section{Water Pollutants -The Aquatic Environment}

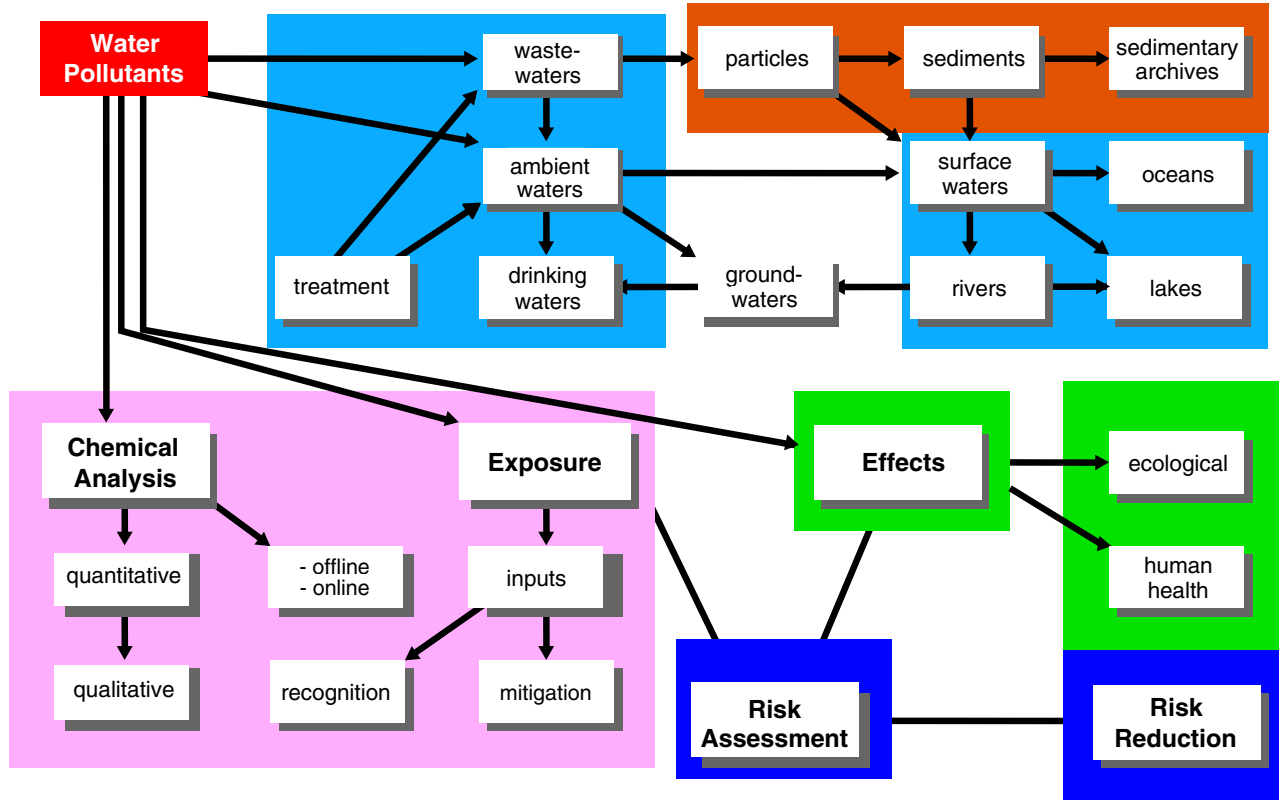

- to evaluate the adverse effects of water contamination on ecosystems and human health;

- to develop models and realistic solutions for the rehabilitation of the environment at selected locations, taking into account the improvement of the socioeconomic status of the affected region;

- to create a basis for decision making regarding the mitigation of negative effects of water contamination, the protection and improvement of the aquatic ecosystems and of drinking water resources, as well as for the sustainable, socioeconomic development and altogether for the improvement of the quality of life in Romania.

From a broader perspective, ESTROM aimed at creating a decision basis for industry and regulators on how to avoid the negative impact of today's environmental contaminants. In addition, ESTROM should identify pertinent aquatic pollutants and suggest mitigating actions.

ESTROM was based on the approaches and concepts described in the following paragraphs.

- Orientation on relevant problems of a national dimension: The problems addressed by ESTROM had a sociopolitical background. They have been converted into scientific questions and were then entrusted to the scientific community for exploration.

- Interdisciplinarity and transdisciplinarity: The combination of different scientific disciplines and the involvement of all relevant stakeholders from researchers to end-users ensured a well-founded overall approach to the solution of the defined problems.

- Added value: ESTROM was not only the sum of individual projects, but rather coordinated and guided research with the purpose to create additional stimulus and insights beyond the individual project level.

- Transfer of results into practice: ESTROM was implementation-oriented. Special efforts for the information of the targeted groups, stakeholders and the public about achieved results and their possible use in practice were made.

The ESTROM programme was jointly launched in 2004 by the SNSF and SDC in cooperation with the Romanian Ministry for Education and Research.

A three-tiered approach led to the selection of the accepted projects based on 40 letters of intents and 22 project outlines, and eventually, out of 12 full research proposals, nine projects were funded. The ESTROM Steering Committee performed the evaluation and selection of the submitted proposals based on the evaluations by external experts. The selection objectives were (a) high scientific and technological quality, (b) broad coverage of the programme area and (c) a reasonable geographical distribution among the universities and research centres in Romania. The latter criterion was set up to avoid a concentration of ESTROM projects in the Romanian capital Bucharest, thereby neglecting research institutions in smaller cities. In addition, really new partnerships should be initiated, which was fulfilled by seven of the nine successful project applications.

The nine partnerships between Swiss and Romanian researchers that were selected in the framework of this programme involved approximately 60 researchers mostly working in Romania. Table 1 and Fig. 2 present an overview of the ESTROM projects listing project titles, acronyms and involved institutions as well as showing the geographical distribution. Each ESTROM project was coordinated by a 
Table 1 ESTROM projects

Overview of a nine ESTROM projects

Integrated Environmental and Socioeconomic Assessment of Impacts by Mining Activities-A Case Study in the Certej River Catchment, Romania-EIMAR

Romanian Academy, Institute of Geography, Bucharest, Romania

Research Institute for Analytical Instrumentation, Cluj-Napoca, Romania

University of Lausanne, Switzerland

Eawag, Swiss Federal Institute of Aquatic Science and Technology, Dübendorf, Switzerland

(Zobrist et al. 2009)

Heavy Metal Contamination in the Vicinity of an Industrial Area near Bucharest $-N E P O L L$

National Research and Development Institute for Nonferrous and Rare Metals, Laboratory of Environment Protection and Eco-technologies, Pantelimon, Romania

Zurich University of Applied Sciences, Institute of Natural Resources Sciences, Wädenswil, Switzerland

(Velea et al. 2009)

Development of an Integrated Water Quality Management System with Application to the Ialomita River Basin, Romania-INWAQ

Technical Unversity, Faculty of Hydrotechnology, Bucharest, Romania

EPFL, Ecole Polytechnique Fédérale de Lausanne, Environmental Science and Technology Institute, Hydrology and Land Management Laboratory, Ecublens, Switzerland

(Soutter et al. 2009)

Eutrophication of Lake Tasaul, Romania: Proposals for Rehabilitation—TASAUL

National Institute for Marine Research and Development "Grigore Antipa", Constanta, Romania

Eawag, Swiss Federal Institute of Aquatic Science and Technology, Dübendorf, Switzerland

(Alexandrow and Bloesch 2009)

Environmental Exposure of Pharmaceuticals in the Somes Valley Watershed, Romania-PHARMSOMES

National Institute of Research and Development for Isotopic and Molecular Technology, Cluj-Napoca, Romania

Iuliu Hateganu University of Medicine and Pharmacy, Cluj-Napoca, Romania

Eawag, Swiss Federal Institute of Aquatic Science and Technology, Dübendorf, Switzerland

(Moldovan and Alder 2009)

Trihalomethane Formation During Water Disinfection in the Four Drinking Water treatmnent Plants of the Somes River Basin, Romania-WAQUA University Babes-Bolyai Cluj-Napoca, Faculty of Environmental Science, Cluj-Napoca, Romania

Institute of Public Health Cluj-Napoca, Cluj-Napoca, Romania

University Babes-Bolyai Cluj-Napoca, Faculty of Physics, Cluj-Napoca, Romania

Water and Sewerage Company Cluj, Cluj-Napoca, Romania

Garda de mediu, Comisariatul Județean Cluj, Cluj-Napoca, Romania

Eawag, Swiss Federal Institute of Aquatic Science and Technology, Dübendorf, Switzerland

(Ristoiu et al. 2009)

Historical Record of Mercury Contamination in the Sediments of the Babeni Reservoir, Olt River, Romania—ORSED

Faculty of Geology and Geophysics, University of Bucharest, Romania

Institute F.-A. Forel, University of Geneva, Versoix, Switzerland

(Bravo et al. 2009) 
Table 1 (continued)

Overview of a nine ESTROM projects

Chemical, Biological and Ecotoxicological Assessment of Pesticides and Persistent Organic Pollutants in the Bahlui River, Romania-POPIASI Technical University "Gheorghe Asachi” Iasi, Department of Environmental Engineering and Management, Iasi, Romania Alexandru Ioan Cuza University Iasi, Faculty of Biology, Centre of Expertise for Sustainable Exploitation of Ecosystems, Iasi, Romania EPFL, Ecole Polytechnique Fédérale de Lausanne, Environmental Science and Technology Institute, Ecublens, Switzerland (Neamtu et al. 2009)

Water and Sediment Dynamics Affecting Nutrient Cycles and Greenhouse Gas Emissions in the Danube Delta-WASEDY

National Institute of Marine Geology and Geoecology, Bucharest, Romania

Eawag, Swiss Federal Institute of Aquatic Science and Technology Swiss Federal Institute of Aquatic Science and Technology, Kastanienbaum, and ETH, Swiss Federal Institute of Technology, Institute of Biogeochemistry and Pollutant Dynamics, Zurich, Switzerland

(Pavel et al. 2009)

Swiss partner affiliated with a public research institution in Switzerland.

The projects began in spring 2005 and lasted 30 months. They increased Romanian research capacities in this scientific field through funding of doctoral students and exchange of scientists. Furthermore, the programme offered additional implementation grants to support dissemination of research results and public participation.
Three programme meetings were organised:

- Kick-off meeting in Cluj-Napoca in May 2005,

- Mid-term meeting in Tulcea in May 2006,

- Final meeting in Iasi in September 2007.

The Tulcea and Iasi meetings were followed by excursions to the Danube delta and to the Moldavian monasteries, respectively.

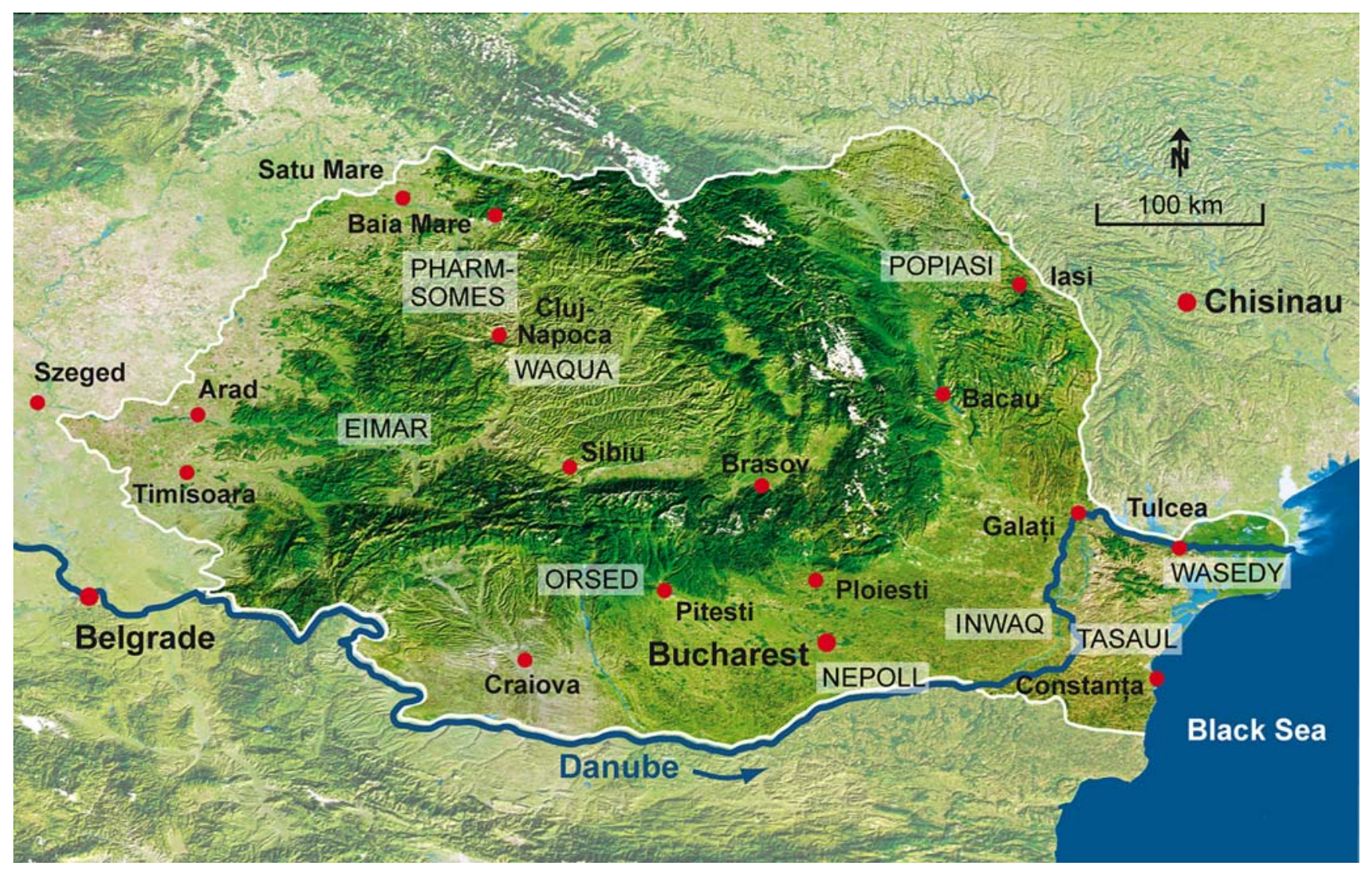

Fig. 2 Map of Romania with locations of the nine ESTROM projects. For project acronyms, see Table 1 
Finally, major findings of the ESTROM projects were presented at the International ESTROM Conference during 35 September 2008 in Bucharest (Giger et al. 2009). At this event, a proceedings publication with ten articles was presented (Panin and Giger 2008). All nine ESTROM projects are presented as summary reports in this Special Issue of Environmental Science and Pollution Research (Alexandrow and Bloesch 2009; Bravo et al. 2009; Moldovan and Alder 2009; Neamtu et al. 2009; Pavel et al. 2009; Soutter et al. 2009; Velea et al. 2009; Zobrist et al. 2009). The presentation files of the talks of the ESTROM meetings and the International Conference are available on the Internet (http://www.cnmp.ro/estrom_en.php? ce=evenimente and http://www.estrom.ch).

The ESTROM projects dealt with research issues on water pollutants with a strong focus on exposure analyses in wastewaters and natural waters including sediments and drinking water. In particular, human exposure, ecotoxic effects and socioeconomic aspects were emphasised. One project dealt with biogeochemical aspects including the emission of greenhouse gases. Another project aimed at an integrated water quality management.

ESTROM encompassed scientific studies on inorganic and organic water pollutants focusing on measuring environmental exposure and evaluating inputs, fate and behaviour in wastewater and in ambient waters. Measured environmental concentrations and evaluation of potential negative effects were the basis for the assessment of risks for the environment and human health.

The successfully performed key elements of the ESTROM projects were:

- Development of reliable methods for qualitative and quantitative measurements of organic and inorganic water contaminants in aqueous and solid samples in aquatic systems, i.e. in wastewaters, ambient waters, drinking waters and sediments.

- Analytical determinations of organic and inorganic chemical contaminants in the aquatic environment to recognise and apportion inputs and occurrences of contaminants in municipal and industrial wastewaters, elucidate fate and behaviour in wastewater and drinking water treatment and assess residual amounts in ambient waters such as rivers, lakes and drinking water.

- The ESTROM investigations focused on environmental pollution by dangerous substances as defined by the European Union Water Framework Directive (EU WFD), Persistent Organic Pollutants (POPs), heavy metals, emerging contaminants (pharmaceuticals and biocidal substances) and nutrients.

- Particles and sediments in aquatic systems are primarily not considered as pollutants per se. However, due to their character as reactive surfaces and their potential as sinks and archives, they play a crucial role within a 'cycling of polluting substances'. Therefore, particles had to be considered, if conclusions are to be drawn on transport, distribution and deposition of pollutants, to assess their potential harm. As sediments often serve as a sink for dangerous substances, they may in turn become the source of secondary pollution after their deposition. Besides, sediments are useful archives for the reconstruction of polluting events and widespread spatial distribution of polluting substances to assess measures of remediation.

The outcomes of the ESTROM programme can help the Romanian authorities to cope with activities of the EU with respect to the implementation of the WFD and derived measures to cope with dangerous substances. The results of the ESTROM programme will be applied to improve the situation regarding water pollutants in Romania by recognising sources of chronic or acute contaminations. An additional important objective was the progress in national and international networking among scientists, administrators and other stakeholders. Three ESTROM programme meetings and the final international conference have contributed substantially to achieve this goal. There is a good chance that the Romanian ESTROM research groups will have improved opportunities to participate in future research projects of the EU and other international or national projects, including SCOPES.

Romanian scientists could benefit significantly from ESTROM activities, as shown by the following three examples:

(1) An ESTROM laboratory will be the Romanian contact point of the proposed permanent European NORMAN network, which will be established as a non-profit association of all interested stakeholders dealing with emerging substances. NORMAN is the acronym for network of reference laboratories, research centres and related organisations for monitoring of emerging environmental substances (see http://www.normannetwork.net). Emerging substances are not necessarily new chemicals. They are substances that have often long been present in the environment but whose presence and significance are only now being elucidated and recognised, respectively.

(2) The scientific network established in Romania by ESTROM now provides a good basis and chance to be linked with other existing Danubian networks, such as the International Association for Danube Research (http://www.iad.gs), the Danube Environmental Forum and the WWF Carpathian Programme, all observers in the International Commission for the Protection of the Danube River (http://www.icpdr.org). Such interdisciplinary networks will strengthen public awareness and participation and enhance the transfer of scientific results into measures of implementation of water protection. 
(3) For the new SCOPES 2009-2012 programme of the Swiss National Science Foundation, several multilateral project proposals of high quality have been submitted, which are based on the network developed within the ESTROM programme.

In conclusion, we are very much convinced that the Romanian-Swiss ESTROM programme has been a very successful endeavour fostering collaboration among scientists of the two countries and forming a sustainable research network with a strong implementation focus.

Acknowledgments The ESTROM programme was primarily financed by two Swiss organisations: the Swiss Agency for Development and Cooperation (SDC) and the Swiss National Science Foundation (SNSF). Additional funding came from the Romanian Ministry for Education, Research and Youth (MECT). All these generous financial supports are highly appreciated. We greatly acknowledge the assistance by the project coordinators of the Committee on International Cooperation of the SNSF Susanne Forster, Jürg Pfister, Jacques André Possa and Elisabeth Schenker. We also thank the members of the Steering Committee including the observers from Romanian and Swiss authorities. For the preparation of the Special ESPR Issue on the ESTROM programme, we profited a lot from the support of Almut B. Heinrich and Moira Ledger.

\section{References}

Alexandrow ML, Bloesch J (2009) Eutrophication of Lake Tasaul, Romania-proposals for rehabilitation. Environ Sci Pollut Res Int 16(suppl 1):42-45
Bravo GA, Loizewau JL, Ancey L, Ungureanu VG, Dominik J (2009) Historical record of mercury contamination in sediments from the Babeni Reservoir in the Olt River, Romania. Environ Sci Pollut Res Int 16(suppl 1):66-75

Giger W, Bloesch J, Zobrist J (2009) ESTROM 2008 International Conference. Environ Sci Pollut Res Int 16(suppl 1):9-13

Moldovan Z, Alder AC (2009) Environmental exposure of pharmaceuticals and musk fragrances in the Somes River before and after upgrading the municipal wastewater treatment plant ClujNapoca, Romania. Environ Sci Pollut Res 16(suppl 1):46-54

Neamtu M, Ciumasu IM, Costica N, Costica M, Bobu M, Nicoara MN, Catrinescu C, Becker van Slooten K, De Alencastro LF (2009) Chemical, biological, and ecotoxicological assessment of pesticides and persistent organic pollutants in the Bahlui River, Romania. Environ Sci Pollut Res Int 16(suppl 1):76-85

Panin N, Giger W (2008) Proceedings of the Romanian-Swiss cooperative research programme "Environmental Science and Technology in Romania” (ESTROM). GeoEcoMarina 14:1-95 http://www.geoecomar.ro/publications

Pavel A, Durisch-Kaiser E, Balan S, Radan S, Sobeck S, Wehrli B (2009) Sources and emission of greenhouse gases in Danube Delta lakes. Environ Sci Pollut Res Int 16(suppl 1):86-91

Ristoiu D, von Gunten U, Mocan A, Chira R, Siegfried B, Kovats MH, Vancea S (2009) Trihalomethane formation during water disinfection in four water supplies in the Somes river basin in Romania. Environ Sci Pollut Res Int 16(suppl 1):55-65

Soutter M, Alexandrescu, Schenk C, Drobot R (2009) Adapting a geographical information system-based water resource management to the needs of the Romanian water authorities. Environ Sci Pollut Res Int 16(suppl 1):33-41

Velea T, Gherghe L. Predica V, Krebs R (2009) Heavy metal contamination in the vicinity of an industrial area near Bucharest. Environ Sci Pollut Res Int 16(suppl 1):27-32

Zobrist J, Sima M, Doganu D, Senila M, Yang H, Popescu C, Roman C, Bela A, Frei L, Dold B, Balteanu D (2009) Environmental and socioeconomic assessment of impacts by mining activities-a case study in the Certej River catchment, Western Carpathians, Romania. Environ Sci Pollut Res Int 16(suppl 1):14-26 